\title{
When Seborrheic Keratosis Is Wearing a Mask
}

\author{
Cristina Sousa, ${ }^{1,2}$ Sebastian Podlipnik, ${ }^{1}$ Susana Puig, ${ }^{1}$ Josep Malvehy ${ }^{1}$
}

1 Dermatology Department, Hospital Clínic, Barcelona, Spain

2 Dermatology Department, Centro Hospitalar de Vila Nova de Gaia/Espinho, Vila Nova de Gaia, Portugal

Key words: seborrheic keratosis, fusion tumor, dermoscopy, dermatology challenge

Citation: Sousa C, Podlipnik S, Puig S, Malvehy J. When seborrheic keratosis is wearing a mask. Dermatol Pract Concept. 2020;10(2):e2020038. DOI: https://doi.org/10.5826/dpc.1002a38

Accepted: January 18, 2020; Published: April 20, 2020

Copyright: $\odot 2020$ Sousa et al. This is an open-access article distributed under the terms of the Creative Commons Attribution License, which permits unrestricted use, distribution, and reproduction in any medium, provided the original author and source are credited.

Funding: None.

Competing interests: The authors have no conflicts of interest to disclose.

Authorship: All authors have contributed significantly to this publication.

Corresponding author: Ana Cristina da Silva Sousa, Rua Conceição Fernandes, 4434-502 Vila Nova de Gaia, Portugal. Email: a.cristina. silvasousa@gmail.com

\section{Case Presentation}

A male patient, 72 years old, had a history of melanoma (AJCC stage IB) located on the left leg. During a regular follow-up visit, we observed an asymmetric, brown, blue-gray plaque with $1.2 \mathrm{~cm}$ maximum diameter, sharply delimited on the right supraclavicular region. On dermoscopy, the

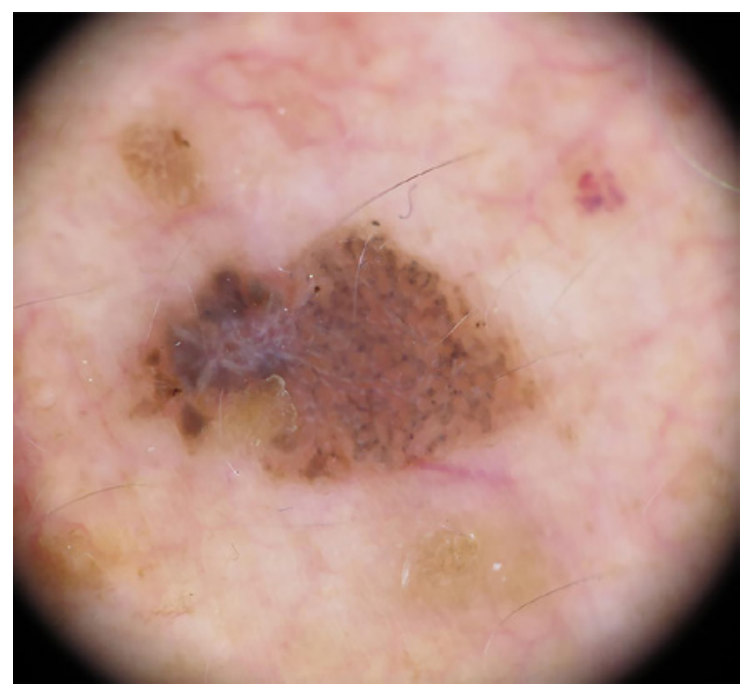

Figure 1. Dermoscopy image of a cutaneous lesion presenting with a multicomponent pattern, with 4 colors, a globular atypical pattern, pseudonetwork, and asymmetrical globules. lesion presented a multicomponent pattern, with 4 colors (brown, gray, blue, and white), a globular atypical pattern, pseudonetwork, and asymmetrical globules. In the left area of the image, it was possible to see a homogenous brown area, with overlapping gray and white shiny structures and ovoid nests which led to the suspicion of a collision tumor of seborrheic keratosis and basal cell carcinoma or melanoma, mainly because of these two distinctive patterns on the same area (Figure 1). The lesion was excised, and the histology was compatible with a seborrheic keratosis.

\section{Teaching Point}

At times, the clinical and dermoscopic diagnosis of seborrheic keratosis is challenging because it can mimic other conditions including basal cell carcinomas or melanomas [1,2].

\section{References}

1. Mansur AT, Yildiz S. A diagnostic challenge: inflamed and pigmented seborrheic keratosis. Clinical, dermoscopic, and histopathological correlation. Dermatol Online J. 2019 Mar 15;25(3). pii: 13030/ qt0w56m5hq.

2. Carrera C. The many faces of seborrheic keratosis. Actas Dermosifiliogr. 2019;110(5):338. 